\title{
On measuring the changes in psychiatric care systems: results in an urban area (Vienna)
}

\author{
StePhan Rudas, Medical Director, Community Mental Health Services Vienna, \\ Gonzagagasse 15, 1010 Vienna, Austria
}

Vienna, a city with a population of 1.5 million, as well as being the capital of Austria is also one of its nine provinces. Care for the mentally ill in Vienna, as elsewhere, was for decades either misguided or poor. The large mental hospitals in the city were seriously overcrowded and understaffed. In the extramural sector, there was an enormous deficit in out-patient and complementary facilities.

Between 1979 and 1988, a basic restructuring of care for the mentally ill was carried out in Vienna, with the aim of providing comprehensive, regionalised and co-ordinated care for the mentally ill. The municipal area was divided into eight catchment areas with populations between 148,000 and 235,000 (Rudas, 1987).

Besides the Psychiatric University Clinic (140 beds), Vienna has two large mental hospitals (Hospital A and Hospital B). In the larger of the two, Hospital A, staffing was increased and an 'internal regionalisation' carried out, with eight regionally responsible sections being created. One of these eight sections was transferred from Hospital A in 1986 to a new general hospital located in the respective catchment area.

Special wards for acute psychiatry, long-term psychiatry, old age psychiatry, and for the mentally handicapped were opened in each regional section in Hospital A. (In Austria, the mentally handicapped are frequently cared for in psychiatric institutions.) The number of in-patients has dropped sharply since 1978.

Patients were never admitted directly to Hospital B, but were all referred from Hospital A. These transfers were discontinued in 1980 , and admissions to Hospital B stopped entirely. This hospital will soon close. The main burden of in-patient care for the mentally ill is therefore borne by Hospital A.

The city of Vienna has established its own agency for the creation and management of new facilities: the Community Mental Health Service. The Community Mental Health Service has established a mental health centre, consisting of an out-patient department and a day clinic, in each of the eight catchment areas. These have been heavily subscribed from the very beginning.

During the night and on weekends, the Community Mental Health Service operates a central psychiatric emergency service. Besides the eight centres, there are also 280 homes and 'half-way houses', and a 'professional rehabilitation centre' with 190 places. Close co-operation between the in-patient and the extramural sector of each catchment area is obligatory. The pattern of care for the mentally ill has therefore changed considerably. The object of this paper is to show the effects of these changes on the lives and the care of patients.

\section{The study}

In the present paper, institution-related basic data from the period before the beginning of the new programmes are compared with the current actual data in order to represent the extent of changes during a ten year period. Subsequently, the extent to which individual groups of patients were affected by the changes is examined on the basis of patient-related data. Some important questions of care are discussed separately. Data will be presented showing:

(a) the impact of improvements on the utilisation of in-patient and out-patient services by several groups of patients (epidemiology of utilisation)

(b) factors affecting the 'pathways' of patients in a defined geographic area (City of Vienna)

(c) number and identity of 'old long-stay patients' and 'new long-stay patients' in the large mental hospital

(d) number and identity of 'long-term' patients in outpatient services (Community Mental Health Centres).

\section{Findings \\ Extent of changes}

On 31 December 1978, there were 3,360 Viennese patients in the two large mental hospitals. By 31 December 1988, there were 992 patients in the two large hospitals or in one of the psychiatric sections. (These figures do not include the Psychiatric University Clinic.) This is a $70.48 \%$ reduction in the number of in-patients. The number of beds in the Psychiatric University Clinic, which does not have a policy of compulsory admission, has remained unchanged at 140. 
There were no dramatic changes in the number of admissions, however. After a slight increase in the number of admissions during the first years, it ultimately decreased slightly. There was though a clear decrease in the number of involuntary admissions, which has always been very high in Vienna. In 1971, $90.9 \%$ of all admissions were involuntary, in 1978 , $82.6 \%$, but in 1988 this had reduced to only $30.87 \%$. This reduction was achieved without any changes to the legal requirements for compulsory admission.

In the extramural sector, the first new facilities of the Community Mental Health Service (CMHS) opened in 1980. In 1983 the CMHS opened the community mental health centres (CMHCs) in each of the eight catchment areas in Vienna. Each centre consists of a psychiatric out-patient department and a day clinic with 15-25 places. Physicians, nursing staff, psychologists, social workers, and occupational therapists work in these centres.

In addition to the eight CMHCs, there are supraregional facilities, including a central psychiatric emergency service for nights and weekends, and an out-patient department for drug addicts. The total number of staff is 164 (1988).

The psychiatric out-patient departments of the CMHS were used by 16,630 persons between 1980 and 1987.

\section{Use of in-patient services}

Only the residents in hospital A (not the other inpatient facilities) are considered.

In Table I, the admission diagnoses from 1974 are contrasted with those in 1986. (In 1974, there had been little or no reform; by 1986 the majority of measures had already been carried out.) The diagnostic allocation of all patients in hospital on 31 December are also compared for 1974 and 1987.

There was no substantial change in the total number of admissions between $1974(5,777)$ and 1986 $(4,816)$. During the course of 1986 , patients from one of the eight catchment areas were no longer admitted to Hospital A, but in the separate psychiatric section in the local general hospital areas. The diagnostic distribution of patients in this section is identical to that of the patients in the mental hospital.

As Table I shows, the relative distribution of diagnoses of patients admitted between 1974 and 1986 changed in two diagnostic groups. The relative share of patients with 'schizophrenic psychoses' rose from $16.0 \%$ of all admissions in 1974 to $23.3 \%$ of all admissions in 1986. Those with 'organic psychoses' (mostly senile and pre-senile dementias) dropped from $27.9 \%$ to $11.0 \%$.

At the end of 1974, there were 2,443 patients in Hospital A, at the end of 1987 , only 906 , a reduction of $62.9 \%$. Table I shows that all diagnostic groups were affected. The most pronounced decrease $(76.7 \%)$ occurred in the group of affective psychoses and in the group of organic psychoses $(69.2 \%)$. The smallest decrease in patient numbers was for 'mental retardation', with $-56.6 \%$.

What can be said by means of a comparison of the admission figures on the one hand and the number of patients on a key date on the other hand as far as the institutional careers of individual diagnostic groups is concerned?

Table I shows that patients with schizophrenic psychoses comprised similar proportions of total admissions and of the hospital population on 31

TABLE I

Utilisation of Mental Hospital A 1974-1986/87: Admissions per year and number of key-date patients in different diagnostic groups

\begin{tabular}{|c|c|c|c|c|c|}
\hline Diagnoses & $\begin{array}{c}\% \text { of all } \\
\text { admissions } \\
1974 \\
(\mathrm{n}=5,777)\end{array}$ & $\begin{array}{c}\% \text { of all } \\
\text { admissions } \\
1986 \\
(\mathrm{n}=4,816)\end{array}$ & $\begin{array}{c}\% \text { of all } \\
\text { key-date } \\
\text { patients } \\
1974 \\
(\mathrm{n}=2,443)\end{array}$ & $\begin{array}{c}\% \text { of all } \\
\text { key-date } \\
\text { patients } \\
1987 \\
(\mathrm{n}=906)\end{array}$ & $\begin{array}{c}\text { Decrease of } \\
\text { number of } \\
\text { key-date } \\
\text { patients } \\
1974-1987 \\
\text { in } \%\end{array}$ \\
\hline \multicolumn{6}{|l|}{ Affective psychoses } \\
\hline (manic-depressive) & 5.9 & 3.8 & 3.7 & 2.3 & -76.7 \\
\hline Schizophrenic psychoses & 16.0 & 25.3 & 31.7 & 27.9 & -67.3 \\
\hline Organic psychoses & & & & & \\
\hline (senile and pre-senile) & 27.9 & 11.0 & 27.0 & 22.4 & -69.2 \\
\hline Alcoholism & 23.3 & 24.6 & 7.5 & 6.9 & -65.6 \\
\hline Mental retardation & 3.2 & 2.2 & 20.4 & 23.9 & -56.6 \\
\hline Other & 23.7 & 33.1 & 9.7 & 16.6 & - \\
\hline Total & 100.0 & 100.0 & 100.0 & 100.0 & -62.9 \\
\hline
\end{tabular}


December. However, patients with a diagnosis of 'alcoholism', while continuing to be admitted in large numbers, comprised a smaller proportion of the hospital population. The primary reason for this is that the duration of stay of patients dependent on alcohol is usually very short. The opposite is the case with patients with mental retardation. They are only admitted in small numbers, but their number in the hospital in each case is very great all the same. Once it has become necessary to admit a patient with mental retardation, the probability of a long stay is evidently high.

\section{First admissions, readmission and 'revolving-door phenomenon'}

In the years before the reform, the ratio of first (lifetime) admissions to readmissions was 60:40 in the mental hospital, By 1988 the ratio was 40:60. If mental-health services are functioning well, fewer patients should be admitted to a large mental hospital for the first time.

The 'revolving-door phenomenon' is repeatedly discussed in connection with drastic reductions in the number of beds. It is feared in this connection that discharged patients, particularly schizophrenics, return for readmission at very short intervals. The data for Hospital A show that this did not happen: $80-81 \%$ of patients admitted are admitted only once that year; $12-13 \%$ have two admissions, $6 \%$ three to five admissions. Less than $1 \%$ of all patients admitted each year have more than five admissions; almost without exception, they are patients abusing alcohol or other substances.

\section{The new out-patient services}

Table II shows the patterns of use of the out-patient departments of the CMHCs by individual diagnostic groups. Of 16,630 patients referred over $1980-87$, the data for 15,528 were evaluated.

The most common diagnoses were alcoholism $(25.2 \%)$, neuroses/personality disorders $(19.7 \%)$, organic psychoses (predominantly dementias) $(16.2 \%)$, and schizophrenic psychoses (16.0\%). A comparison with the data from Hospital A (see also Table I) shows these diagnostic rates to be similar to those for in-patients. Only the share of CMHC patients with organic psychoses is clearly lower than the share of this diagnostic group in hospital admissions. The CMHCs thus mainly treat the same groups of patients as Hospital A. It was possible to avoid a situation in which patients with certain diagnoses were treated in the mental hospital and with other diagnoses (above all neuroses) were treated in the CMHCs.

Table II also gives figures for CMHC patients previously admitted to hospital. There are clear differences between the individual diagnostic groups. Only $29.4 \%$ of all CMHC patients with a diagnosis of organic psychosis had previously been in-patients, compared with $86.9 \%$ of schizophrenics. Half of all CMHC patients had previously been in-patients.

\section{Reduction in bed numbers: who stayed in the hospital?}

Great reductions in the number of beds in mental hospitals are necessarily accompanied by a decrease in the number of long-stay patients and the shorter length of stay for acute patients. Of the 2,351 patients who were in Hospital A on 31 December 1977, 846

TABLE II

Utilisation of Community Mental Health Centres in Vienna (1980-1987): Diagnoses of patients in CMH Centres 1980-1987 $(\mathrm{n}=15,528)$ CMHC patients with in-patient precare in $\%$ in different diagnostic groups

\begin{tabular}{|c|c|c|c|}
\hline Diagnoses & $\begin{array}{c}\text { \% of all } \\
\text { CMHC patients } \\
(\mathrm{n}=15,528)\end{array}$ & $\begin{array}{l}\text { Psychiatric } \\
\text { prehospitalisation } \\
\text { before first contact } \\
\text { with CMHC in } \%\end{array}$ & $\begin{array}{c}\text { CMH contacts } \\
\text { of a patient } \\
\text { during a year } \\
\text { (average) }\end{array}$ \\
\hline \multicolumn{4}{|l|}{ Affective psychoses } \\
\hline $\begin{array}{l}\text { (manic-depressive) } \\
\text { Schizophrenic psychoses }\end{array}$ & $\begin{array}{r}6.9 \\
16.0\end{array}$ & $\begin{array}{l}59.1 \\
86.9\end{array}$ & $\begin{array}{l}12.5 \\
25.6\end{array}$ \\
\hline Organic psychoses & & & \\
\hline (senile and pre-senile) & 16.2 & 29.4 & 5.3 \\
\hline Alcoholism & 25.2 & 45.3 & 13.4 \\
\hline Mental retardation & 3.5 & 67.9 & 37.6 \\
\hline Other & 32.2 & - & - \\
\hline (Neuroses) & (19.7) & - & - \\
\hline (Drug addiction) & (3.3) & - & - \\
\hline Total & 100.0 & 49.8 & 16.4 \\
\hline
\end{tabular}


(36\%) were admitted during 1977 and were thus acute patients at that time; 1,505 patients $(64 \%)$ had already been in the hospital for more than 12 months (long-stay patients).

On 31 December 1987, of the total of 906 patients, $367(40.5 \%)$ had been admitted during the course of the year and $539(59.5 \%)$ had been in the hospital for mpre than 12 months. The number of acute patients therefore dropped by $479(56.62 \%)$ in ten years, the number of long-stay patients by $966(64.19 \%)$.

Of those 2,351 patients who were in Hospital A in $1977,271(11.53 \%)$ were still in the hospital at the end of 1987. A further 268 patients were admitted during 1978-86 and were still in the hospital at the end of 1987. The total number of patients with a duration of stay exceeding 12 months was thus 539 in Hospital A on 31 December 1987.

Of all long-stay patients, $35.62 \%$ had a diagnosis of 'mental retardation', $26.35 \%$ of 'schizophrenic psychoses', and $24.68 \%$ of 'organic psychoses' (dementia). These three diagnostic groups accounted for $86.65 \%$ of all patients who had been in hospital for more than 12 months on 31 December 1987.

A few months later, on 15 April 1988, we examined the group of long-stay patients (their number having dropped to 497 in the meantime) with respect to their age. Of the 497 long-stay patients, $52.72 \%$ were over 60 . Only $32.25 \%$ of the acute patients belonged to this age group. Thus the share of persons over 60 years of age is especially high among the long-stay patients. Besides diagnosis, age is therefore also a factor for a long stay in a mental hospital.

\section{New long-stay patients}

For those in hospital on 31 December 1987 who had been admitted between 1983 and 1986, we calculated the probability of a length of stay of more than one year for individual diagnostic groups (i.e. the prob- ability of becoming a new long-stay patient). 'Mental retardation' was particularly associated with a long hospital stay. Of every 100 admissions in this diagnostic group, 8.06 lead to long-term hospitalisation compared with 0.7 for 'schizophrenic psychoses', and 0.23 for 'alcoholism'. Under the diagnosis 'dementia', 4.6 of every 100 admissions led to longterm hospitalisation. At present there are 3.4 new long-stay patients per 100,000 population in Vienna per year, of which $0.4-0.5$ are accounted for by 'schizophrenia'.

\section{Comparison of new long-stay with old long-stay patients}

First, the diagnostic data were examined for the 334 patients who had been in Hospital A for more than five years on 31 December 1987 (old long-stay patients). Of these old long-stay patients, $47.01 \%$ had a diagnosis of mental retardation $32.33 \%$ of schizophrenic psychoses.

The diagnostic data of those 205 patients who had been in the hospital for between 12 months and 5 years on the same date (new long-stay patients) were different. There was a considerably lower proportion $(17.07 \%)$ of patients with mental retardation, and also a lower proportion with 'schizophrenic psychoses' $(16.59 \%)$. The proportion of patients with organic psychoses (primarily dementias) was high at $47.80 \%$. In Table III, the diagnostic distribution of old long-stay patients is contrasted with that of new long-stay patients. It turned out that $52.72 \%$ of all long-stay patients were aged over 60 . Of all new longstay patients, $61.11 \%$ were 60 or more, compared with only $47.95 \%$ of the old long-stay patients. The relative old age of the long-stay patients is thus primarily ascribable to the group of the new long-stay patients. This is surely connected with the limits of life expectancy in the group of the old long-stay patients.

TABLE III

'Old long stays' (hospitalised more than 5 years) and 'new long stays' (hospitalised 12 months-5 years) in Hospital A on 1987 key date in diagnostic groups

\begin{tabular}{lcc}
\hline Diagnoses & $\begin{array}{c}\text { \% of 'old long stays' } \\
(\mathrm{n}=334=100 \%)\end{array}$ & $\begin{array}{c}\text { \% of 'new long stays' } \\
(\mathrm{n}=205=100 \%)\end{array}$ \\
\hline Schizophrenic psychoses & 32.33 & 16.59 \\
Affective psychoses & 0.90 & 1.95 \\
Organic psychoses & & 47.80 \\
(senile and presenile) & 10.48 & 17.07 \\
'Mental retardation' & 47.01 & 16.56 \\
Other & 9.28 & 100.00 \\
Total & 100.00 & \\
\hline
\end{tabular}




\section{Long-term patients in the CMHCs}

For CMHC patients in $1987(n=5,033)$, those who had their first contact before 1 January 1985 are considered long-term out-patients. Patients whose contact in 1987 was their first are considered acute patients. Patients from 1987 with first contacts to the CMHC in the years 1985 and 1986 are an intermediate group. The long-term patients comprised significantly more of the diagnostic groups 'affective psychoses' and 'schizophrenic psychoses'. The intermediate group had a frequent diagnosis of paranoid syndromes. Organic psychoses, alcoholism, neuroses, and personality disorders, as well as 'other diagnoses', were significantly more common among acute patients. Patients who received longerterm care from the CMHC thus frequently belonged to the group 'endogenic psychoses'. Patients with dementias, alcoholism, and neuroses are more frequently cared for only briefly.

\section{Comments}

These results have shown that a reduction in the number of beds in mental hospitals does not lead to a significant increase in the number of admissions. Wherever there are community mental health services while bed numbers are being reduced, they can be seen to be of benefit (Häfner \& Klug, 1982). This particularly applies where it is possible to direct such services to patients from the large mental hospitals (Rudas, 1986). This can avoid the negative aspects of deinstitutionalisation (Lamb, 1988).

Even under new basic conditions, there are still long-term patients. Old long-term patients remain in the hospital, and new ones are admitted. At present, older patients in particular tend to be admitted for longer (Jakubaschk \& Kopp, 1989). Those few authors who report contrary findings would seem not to have taken the fact into account that the average stay of very old patients is limited by their life expectancy.

In the extramural sector, primarily schizophrenic patients and patients with affective psychoses are cared for over longer periods of time, but those with dementias drop out from treatment more frequently.

During the first eight years of their existence, more than 16,000 persons (1.1\% of the total population) have used the CMHCs. These patients were cared for with a staff of approximately 160 (0.11 employees per 1,000 inhabitants). These results show the great potential of an integrated, regionalised psychiatric system of care, and the importance of co-ordinating in-patient and out-patient services.

\section{References}

HÄFNER, H. \& KLUG, J. (1982) The impact of an expanding community mental health service on patterns of bed usage: evaluation of a four-year period of implementation. Psychological Medicine, 12, 177-190.

JAKUBASCHK, J. \& KOPP, W. (1989) On characterizing new psychiatric long-stay patients. Social Psychiatry and Psychiatric Epidemiology, 24, 88-95.

LAMB, R. H. (1988) Deinstitutionalisation at the crossroads. Hospital and Community Psychiatry, 39, 941-945.

RUDAS, S. (1986) Comprehensive mental services - who needs them? Acta Psychiatrica Belgica, 86, 630-635.

- (1987) Planning and evaluation of comprehensive psychiatric care systems. Neurologia et Psychiatrica, 10, Suppl. 1, 51-53. 